В статье анализируются этиологические и патогенетические факторы (в том числе факторы иммунопатогенеза) хронической обструктивной болезни легких (ХОБЛ) и метаболического синдрома (МС), приводятся данные о клиникопатогенетических особенностях сочетанной патологии, подчеркивается общность факторов риска и отдельных звеньев патогенеза при синтропии.

Клинико-патогенетические особенности коморбидности ХОБЛ и МС тесно связаны с выраженностью хронического «метаболического» воспаления, индуцируемого элементами жировой ткани. Функциональные и биохимические нарушения, регистрируемые при МС (инсулинорезистентность, гипергликемия, дислипидемия), рассматриваются как факторы, способствующие дисфункции компонентов врожденного и адаптационного иммунитета.

В обзоре сформулирован ряд нерешенных вопросов патогенеза коморбидной патологии, изучение которых необходимо для поиска механизмов, лежащих в основе взаимоотягеающего влияния ХОБЛ и МС. Принимая во внимание разнообразие клинико-лабораторных эквивалентов МС, авторы подчеркивают актуальность дальнейших исследований патогенетических особенностей хронического воспаления, ассоциированного с коморбидностью основных компонентов МС и ХОБЛ, для разработки эффективных способов профилактики и патогенетической терапии сочетанной патологии.

КЛЮЧЕВЫЕ СЛОВА: коморбидность; хроническая обструктивная болезнь легких; метаболический синдром; хроническое воспаление; патогенез.

\title{
ETIOPATHOGENETIC PARALLELS AND UNRESOLVED ISSUES OF PATHOGENESIS OF COMORBIDITY COPD AND METABOLIC SYNDROME (REVIEW)
}

\author{
(c) Olga V. Voronkova*, Tatyana V. Saprina, Ekaterina B. Bukreeva, Anastasia P. Zima
}

Siberian State Medical University, Tomsk, Russia

The review analyzes the etiological and pathogenetic factors (including immunopathogenesis factors) of chronic obstructive pulmonary disease (COPD) and metabolic syndrome (MS), cites data on clinical and pathogenetic characteristics of combined pathology, emphasizes the commonality of risk factors and individual links of pathogenesis in syntropy.

The clinical and pathogenetic features of the comorbidity of COPD and MS are closely related to the severity of chronic "metabolic" inflammation induced by elements of adipose tissue. Functional and biochemical disorders recorded in metabolic syndrome (insulin resistance, hyperglycemia, dyslipidemia) are considered as factors contributing to dysfunction of the components of innate and adaptive immunity.

The review formulates a number of unresolved issues of the pathogenesis of comorbid pathology, the study of which is necessary to search for the mutual aggravating effect of COPD and MS mechanisms. In view of the clinical and laboratory metabolic syndrome equivalents variety, the authors emphasize the relevance of future studies of the pathogenetic features of chronic inflammation associated with the comorbidity of the main components of metabolic syndrome and COPD, to develop effective methods of prevention and pathogenetic therapy of comorbid pathology.

KEYWORDS: comorbidity; chronic obstructive pulmonary disease; metabolic syndrome; chronic inflammation; pathogenesis.

\section{ПОИСК И КРИТЕРИИ ОТБОРА ЛИТЕРАТУРНЫХ источников}

При подготовке обзора были использованы следующие полнотекстовые и библиографическо-реферативные базы данных: Национальной медицинской библиотеки США (PubMed, Medline); Научной электронной библиотеки eLIBRARY.RU; научной электронной библиотеки КиберЛенинка (cyberleninka.ru); электронно-библиотечной системы Book-Up; Национальной электронной библиотеки (rusneb.ru).
Поиск источников первичной информации осуществлялся на глубину 10 лет (2010-2020 гг.) по следующим ключевым словам (в англоязычных базах данных - с соответствующим переводом): коморбидность; хроническая обструктивная болезнь легких; метаболический синдром; ожирение; системное хроническое воспаление; ожирение и иммунитет; патогенез ХОБЛ; патогенез метаболического синдрома; ожирение и функция легких; коморбидность ХОБЛ и метаболического синдрома; биомаркеры ХОБЛ; биомаркеры метаболического синдрома; эпидемиология ХОБЛ и метаболического синдрома; 
цитокины и воспаление; адипокины и воспаление; ожирение и воспаление; клинические особенности коморбидности ХОБЛ и метаболического синдрома; иммунитет и ХОБЛ. При подготовке статьи были проанализированы ключевые рецензируемые научные публикации, рекомендованные комитетом по науке Глобальной инициативы по обструктивной болезни легких в 2020 г. (Global Strategy for Prevention, Diagnosis and Management of COPD, GOLD, 2020).

\section{ВВЕДЕНИЕ}

Коморбидность хронических заболеваний является одной из важных особенностей современной патологии человека. Профилактика и диагностика заболеваний, являющихся компонентами синтропии, а также выбор методов лечения и реабилитации коморбидных больных, как правило, требуют мультидисциплинарного подхода. На сегодняшний день основные фундаментальные и прикладные аспекты проблемы коморбидности (синтропии, полипатии) можно сформулировать следующим образом: 1) недостаточное изучение значимости и вклада отдельных этиологических факторов (как предрасполагающих, так и средовых) среди множества причин основного и сопутствующего заболеваний в формирование полипатии; 2) недостаточное понимание роли отдельных, нередко взаимообусловленных, патогенетических факторов в механизмах развития синтропий и, как следствие, непонимание причин их клинико-патогенетической разнородности; 3) высокий риск осложнений лекарственной терапии при комбинированном назначении большого количества препаратов, даже в пределах их терапевтических доз.

Формирование полипатии наиболее характерно для хронических заболеваний, обусловленных наследственной предрасположенностью, таких как сахарный диабет, диффузные заболевания соединительной ткани, язвенная болезнь желудка и двенадцатиперстной кишки, гипертоническая болезнь, атеросклероз и др. [1, 2].

Одной из таких патологий является хроническая обструктивная болезнь легких (ХОБЛ) - мультифакториальное заболевание со сложным полигенным механизмом наследования. Предрасполагающими наследственными факторами ХОБЛ являются: генетически обусловленная недостаточность ингибиторов сериновых протеаз, а также низкая активность ферментов биотрансформации ксенобиотиков и антиоксидантной защиты (глутатион-S-трансферазы (GST), микросомальной эпоксидгидролазы (mEH), гемоксигеназы-1 (HO-1), супероксиддисмутазы (SOD), ферментов семейства CYP (CYP2S1, CYP2A6 и др); НАД(Ф) Н-хинон оксидоредуктазы 1 (NQ01); гаптоглобина (компонент фракции альфа-2-глобулинов крови)). Определенную роль в наследственной предрасположенности играют генетические полиморфизмы, определяющие высокую активность ферментов семейства матриксных металлопротеиназ (МMP-1, MMP-3, MMP-9, MMP-12), полиморфизм генов медиаторов воспаления (витамин-D-связывающего протеина (VDBP), трансформирующего фактора роста (TGF- $\beta 1)$, цитокинов (TNFa, IL-1, IL-8)) и их рецепторов [3-6].

\section{КОМОРБИДНОСТЬ ПРИ ХРОНИЧЕСКОЙ ОБСТРУКТИВНОЙ БОЛЕЗНИ ЛЕГКИХ: МЕСТО МЕТАБОЛИЧЕСКОГО СИНДРОМА}

Отечественные и зарубежные эпидемиологические исследования свидетельствуют о том, что для пациентов с ХОБЛ характерен широкий спектр коморбидности, который включает как соматические, так и психические расстройства: артериальная гипертензия (в 35-70\% случаев ХОБЛ), ишемическая болезнь сердца, атеросклероз коронарных сосудов с тромботическими осложнениями (от 20 до 50-60\%), бронхиальная астма (до 21\%), ожирение (в среднем у 40\% больных) или, напротив, снижение индекса массы тела (14\%), онкологические заболевания (наиболее часто - рак легких до 30\%), остеопороз (до 70\% случаев ХОБЛ), сахарный диабет (31\%), дезадаптивные и психические расстройства [7-10].

В определении ХОБЛ в Глобальной стратегии профилактики, диагностики и лечения (Global Strategy for Prevention, Diagnosis and Management of COPD, GOLD, 2020) подчеркнуто влияние сопутствующей патологии на заболеваемость и смертность. Акцент сделан на заболевания сердечно-сосудистой системы, остеопороз, рак легкого, гастроэзофагеальную рефлюксную болезнь, бронхоэктатическую болезнь, синдром обструктивного апноэ сна, метаболический синдром (МC) и сахарный диабет, тревожно-депрессивные расстройства. Кроме того, обсуждается влияние множественной коморбидности на тяжесть клинического течения ХОБЛ, частоту обострений, качество жизни пациентов, подчеркнута актуальность поиска безопасных и эффективных способов лечения осложненных форм, особенно у пожилых лиц [10].

Несмотря на многочисленные эпидемиологические и клинические данные, подтверждающие важную связь компонентов МС с нарушением функции органов дыхания, ХОБЛ в перечень заболеваний, прямо ассоциированных с MC, не входит. При этом МС встречается у больных ХОБЛ, по разным данным, с частотой от 20 до 50\% [9, 11-14].

Следует также отметить, что современные эпидемиологические исследования направлены в основном на изучение распространенности случаев МС среди пациентов с ХОБЛ, тогда как данные о заболеваемости ХОБЛ у пациентов с МС, являющимся первичной патологией, в современной литературе единичны. Так, одной из задач исследования, проведенного в 2017 г. в Университете Бари Альдо Моро в Италии, являлось изучение коморбидного спектра у больных с МС, в том числе частоты заболеваемости ХОБЛ. В результате исследования было установлено, что распространенность заболевания среди амбулаторных пациентов с МС составила 22\% [15].

\section{ПАТОГЕНЕТИЧЕСКИЕ ФАКТОРЫ КОМОРБИДНОСТИ ХРОНИЧЕСКОЙ ОБСТРУКТИВНОЙ БОЛЕЗНИ ЛЕГКИХ И МЕТАБОЛИЧЕСКОГО СИНДРОМА}

Формирование клинически различных проявлений болезни (фенотипов: бронхитического, эмфизематозного, ХОБЛ с частыми обострениями, ХОБЛ с повышенным количеством эозинофилов, ХОБЛ в сочетании с бронхиальной астмой и др.), вызванных идентичными 
этиологическими факторами, по-видимому, свидетельствует о различиях в механизмах патогенеза. В сравнительном аспекте при разных клинико-патогенетических вариантах ХОБЛ в литературе рассматриваются следующие патогенетические факторы: токсико-воспалительные иммуномодулирующие эффекты экзогенных химических веществ, изменение баланса про- и противовоспалительных цитокинов, вызванный медиаторами воспаления и этиологическими факторами апоптоз иммунокомпетентных клеток, метаболический эффект медиаторов воспаления, окислительный стресс, недостаточность эффероцитоза нейтрофилов, аутоиммунные реакции и др. [16-19].

Воспалительный ответ при ХОБЛ включает как врожденные, так и адаптивные иммунные реакции, индуцированные активированными дендритными клетками. В просвете и стенке дыхательных путей, а также В легочной паренхиме наблюдается лейкоцитарная инфильтрация, объединяющая все виды фагоцитов, Т- и В-лимфоциты $[17,19,20]$. Несмотря на большое количество исследований, направленных на изучение особенностей иммунного ответа при ХОБЛ, к настоящему времени отсутствуют четкие представления об иммунологических фенотипах, характеризующих различные клинические варианты болезни. Тем не менее полученные результаты свидетельствуют о сопряженности по ряду факторов фенотипа иммунного ответа с особенностями клинического течения заболевания. Было установлено, что у пациентов с неосложненным течением болезни, с редкими сезонными обострениями и умеренной степенью ограничения скорости воздушного потока, преобладает Th1-тип иммунного ответа с характерным для него цитокиновым фоном и субпопуляционным составом лимфоцитов в крови (повышение концентрации TNFa, IFNy и количества CD3 ${ }^{+}$CD126+-клеток, экспрессирующих IL-6R). У больных со средней степенью ограничения скорости воздушного потока, выраженным влиянием ХОБЛ на качество жизни и частыми обострениями превалировал Th17-фенотип иммунного ответа на фоне высокой концентрации IL-21, IL-6 и TGF- $\beta 1$ в крови и численное преобладание $\mathrm{CD} 4^{+} \mathrm{CD} 126^{+}$-лимфоцитов) [21-23].

Результаты ряда исследований, посвященных изучению морфофункционального состояния факторов иммунной защиты, свидетельствуют о функциональной недостаточности факторов врожденного и адаптационного иммунитета при частых обострениях ХОБЛ, а именно: дефект мукоцилиарного клиренса мокроты; дефицит slgA и дефензинов; снижение уровня $\mathrm{CD} 25^{+}$-, $\mathrm{CD}_{11+-}^{+}, \mathrm{CD}^{+} 5^{+}$, , CD16+- и Treg-CD4+CD25+FoxP3-лимфоцитов; нарушение фагоцитоза; недостаточность иммуноглобулинов, в частности $\operatorname{lgG3}$, дисбаланс цитокинов (снижение выработки IFN $\gamma$, IL-2 и, напротив, повышение TGF $\beta$, IL-1 $\beta$, IL-10, IL-4, IL-6, IL-13, обладающих профибротическим действием) [16].

В литературе обсуждается также роль аутоиммунных реакций в иммунопатогенезе ХОБЛ. Воздействие компонентов сигаретного дыма (карбонилирование белков) либо повреждение клеток и тканей веществами, образующимися в результате окислительного стресса, приводят к образованию аутоантител с последующей инфильтрацией легочной ткани цитотоксическими CD8 ${ }^{+}$
Т-клетками, снижением содержания $\mathrm{CD}^{+} \mathrm{CD} 25^{+} \mathrm{FoxP} 3$ регуляторных Т-клеток, выработкой антител против эластина, противоэндотелиальных антител, образованием иммунных комплексов с последующей субэпителиальной и субэндотелиальной фиксацией; активацией компонентов комплемента; усилением продукции IFNү и IL-10 CD4+-лимфоцитами, стимулированными антиэндотелиальными антителами [24].

Характеристика состояния иммунной системы при MC, а также механизмов его иммунопатогенеза представляется затруднительной, вероятно, ввиду широкого спектра его клинических эквивалентов. В этом случае следует рассматривать особенности иммунологической реактивности при таких состояниях, как инсулинорезистентность (в доступной литературе сведения, более или менее комплексно характеризующие иммунный статус, отсутствуют), сахарный диабет (данные многочисленны), дислипидемия (представлены результаты единичных исследований), а также ожирение. Иммунологическая характеристика последнего достаточно подробно представлена в современной отечественной и зарубежной литературе. Более того, большинство исследователей определяют роль иммунной системы в патогенезе метаболического синдрома именно в контексте вовлечения различных ее звеньев в реакции системного хронического воспаления, индуцируемого элементами жировой ткани. Однако эти данные носят противоречивый характер. По мнению одних исследователей, при воспалении на фоне ожирения преобладает гуморальный тип иммунного ответа. Другие авторы считают, что имеет место иммунное отклонение в сторону клеточного иммунитета, причиной которого является модулирующее действие лептина на цитокинпродуцирующую активность регуляторных клеток - моноцитов и нейтрофилов [25-30].

MC характеризуется увеличением массы висцерального жира, снижением чувствительности периферических тканей к инсулину и гиперинсулинемией, которые вызывают развитие нарушений углеводного, липидного, пуринового обменов и артериальной гипертонии. В ряде исследований была обнаружена корреляционная взаимосвязь между отдельными компонентами МС (дислипидемия, гипергликемия натощак, абдоминальное ожирение, гипертония) и нарушениями дыхательной функции как у пациентов с сердечно-сосудистыми и респираторными заболеваниями, так и у лиц без сердечно-легочной патологии.

Одним из основных компонентов МС, оказывающих влияние на функцию внешнего дыхания, является абдоминальное ожирение. Помимо механического влияния избыточного объема жировой ткани, в патогенезе нарушений легочной функции рассматривается участие широкого спектра биологически активных веществ, вырабатываемых жировыми клетками. Основные клетки жировой ткани (адипоциты) синтезируют целый ряд пептидных гормонов (лептин, адипонектин, резистин, висфатин), хемокинов и цитокинов (моноцитарный хемотаксический протеин, TNF-a, IL-1, II-6, IL-8), других биологически активных веществ (ингибитор активатора плазминогена-1, простагландины, лейкотриены и др.) $[28,31,32]$. 
Содержащиеся в жировой ткани стромальные и иммунные клетки, составляющие так называемый стромально-васкулярный паттерн, также обладают мощной секреторной активностью. Несколько исследований в нашем университете были посвящены изучению морфофункционального статуса клеточных элементов жировой ткани на фоне ее хронического воспаления. В биоптатах жировой ткани, а также в культурах мезенхимальных стромальных клеток наблюдалось статистически значимое повышение концентрации провоспалительных цитокинов (IL-1- $\beta$, IL-8, TNF-a), а также моноцитарного хемотаксического белка-1. Морфологическая картина воспаления в жировой ткани характеризуется лейкоцитарной инфильтрацией нейтрофильного и лимфоцитарного характера на начальном этапе, а в отдаленном периоде - количественным преобладанием макрофагов. Соответствующий структурно-функциональный паттерн составляет морфологическую основу такого феномена, как метаболическое воспаление жировой ткани, триггерами которого выступают не инфекционные агенты, а нутриенты и продукты метаболизма [33].

Было высказано предположение, что метаболические условия активации, включая концентрацию глюкозы, инсулина, жирных кислот, оказывают влияние на функциональный фенотип макрофагов в жировой ткани. Так, метаболический фон воспаленной жировой ткани способствует сдвигу баланса M1/M2-макрофагов и численному доминированию макрофагов М1-фенотипа, которые характеризуются секрецией провоспалительных цитокинов и оксида азота, тогда как альтернативно активированные CD206 ${ }^{+}$макрофаги (M2), обладающие противовоспалительной активностью за счет секреции IL-10 и антагониста рецепторов IL-1 $\beta$ в жировой ткани не присутствуют. Таким образом, провоспалительные факторы, которые вырабатывают клетки в жировой ткани (адипокины, адгезивные молекулы, хемоаттрактанты, цито- и хемокины) становятся патогенетическим звеном «порочного круга», способствующего прогрессированию воспаления [34, 35].

Патогенез коморбидной патологии представляет собой комбинацию патогенетических факторов, общих для основного и сопутствующего заболевания и взаимодействующих друг с другом по принципу взаимного отягощения. Для хронических заболеваний легких, таких как ХОБЛ, бронхиальная астма, рестриктивная легочная патология, метаболические нарушения могут увеличивать риск обострений на фоне гипергликемии, гипертриглицеридемии, повышения уровня С-реактивного белка [36-38].

Обсуждается концепция «метаболического иммунитета», который представляет собой совокупность метаболических факторов (биохимических феноменов) с иммунотропным эффектом. Нормальное функционирование факторов иммунной системы в организме возможно только на фоне сбалансированных метаболических процессов. Таким образом, спектр функциональных и биохимических нарушений, регистрируемый при МС (инсулинорезистентность, гипергликемия, дислипидемия) можно рассматривать как фактор, способствующий иммунологической дисфункции при коморбидной патологии. При этом на фоне генетически предопределенной недостаточной емкости компонентов антиоксидантной системы усиливается перекисное окисление липидов, что приводит к структурным нарушениям иммуноком- петентных клеток, увеличению их проницаемости, накоплению в крови иммуносупрессивных факторов (ацилгидроперекисей, диеновых конъюгатов жирных кислот, малонового диальдегида, аномальных метаболитов липидного обмена), разобщению окислительного фосфорилирования, снижению энергообеспечения клеток, угнетению синтеза ферментов. Возникающие нарушения структурного и энергетического гомеостаза иммунокомпетентных клеток могут быть сформированы как по типу метаболической иммуносупрессии, так и по типу гиперреактивности [39].

Например, гиперлипидемия как один из патогенетических факторов МС может вносить весомый вклад в развитие системной воспалительной реакции и опосредует нарушение функции легких. Свободные жирные кислоты в высокой концентрации способны индуцировать функциональную активность клеток системы мононуклеарных фагоцитов через активацию паттерн-распознающих рецепторов, в частности, TLR4. Рецептор-опосредованные сигнальные пути приводят к повышению активности транскрипционных факторов (NF-kB, AP-1 и др.) и экспрессии генов, ответственных за наработку медиаторов воспаления. Известно также, что насыщенные жирные кислоты через активацию Nod-подобных рецепторов семейства NALP (NLRP3) способствуют образованию в клетках молекулярных платформ (инфламмасом), на которых происходят процессинг и образование зрелой активной формы провоспалительных цитокинов (IL-1 $\beta$ и IL-18) [37].

Клинико-патогенетические особенности сочетанной патологии тесно связаны с параметрами системного воспаления. У лиц с сочетанной патологией изменения в балансе между про- и противовоспалительными факторами носят более стойкий и выраженный характер. Так, установлено более высокое содержание в крови С-реактивного белка, фибриногена, концентрации IL-6, IL-8, TNF-a, что свидетельствует об интенсивности системной воспалительной реакции у больных с сочетанной патологией по сравнению с параметрами у пациентов без коморбидного фона $[40,41]$. При оценке цитокинового профиля, уровня биомаркеров легочной патологии и адипокинов у больных ХОБЛ и ожирением было выявлено повышение в крови концентрации лептина, С-реактивного белка, IFN- $\gamma$, TNF- $a$, TNF-R1, TNF-R2 по сравнению с соответствующими показателями у пациентов с нормальной массой тела [42]. При сочетании ХОБЛ и МС зарегистрирован более низкий уровень адипонектина в плазме, чем при изолированной ХОБЛ [33].

Исследования оксидантно-антиоксидантного статуса у больных ХОБЛ, сочетающейся с МС, показали, что при сочетанной патологии наблюдается более выраженный дисбаланс оксидантно-антиоксидантных систем, чем при изолированной ХОБЛ. В частности, выявлено повышенное содержание альдегид- и кетондинитрофенилгидразонов нейтрального и основного характера, диеновых конъюгатов, кетодиенов и сопряженных триенов, малонового диальдегида в плазме крови и эритроцитах; отмечено снижение активности каталазы и уровня восстановленного глутатиона на фоне компенсаторного увеличения содержания церулоплазмина, активности глутатионпероксидазы и глутатион-S-трансферазы [43]. 
Ряд исследований, касающихся изучения особенностей клинической картины и качества жизни пациентов с ХОБЛ, осложненной МС, свидетельствуют о том, что у больных с коморбидной патологией наблюдается более тяжелое течение основного заболевания с более частыми обострениями, требующими обязательной госпитализации пациента. Так, для ХОБЛ, осложненной МС, характерна более выраженная клиническая симптоматика (степень одышки, низкая толерантность к физической нагрузке). Среди жалоб у коморбидных пациентов превалируют следующие: влажный кашель с большим количеством мокроты, отеки конечностей, головная боль, нарушение сна. При физикальном обследовании чаще выявляются цианоз, тахикардия, сухие хрипы в легких, увеличение печени и периферические отеки. Результаты спирографии у больных с сочетанной патологией свидетельствуют о нарушениях дыхания, чаще смешанного типа (рестриктивные и обструктивные), при этом установлена взаимосвязь между формированием рестриктивных нарушений и наличием ожирения. Рентгенологическая картина осложненной метаболическим синдромом ХОБЛ характеризуется усилением легочного рисунка; при электрокардиографии в 3 раза чаще, чем у больных с изолированной ХОБЛ, регистрируются признаки перегрузки правых отделов сердца. Установлено, что ишемическая болезнь сердца у больных ХОБЛ на фоне метаболического синдрома формируется в среднем на 9 лет раньше, чем при изолированной ХОБЛ; чаще развиваются нарушения сердечного автоматизма и проводимости; острые нарушения мозгового кровообращения у пациентов с сочетанной патологией регистрируются на 12,3\% чаще, чем при отсутствии метаболических расстройств [12, 44-51].

Общность некоторых этиологических факторов и ряда патологических процессов определяет актуальность поиска универсальных механизмов развития синтропии ХОБЛ и метаболического синдрома. Анализ литературы показал, что наиболее обсуждаемым в последние годы процессом, который объединяет компоненты метаболического синдрома и ассоциированные с ним заболевания, является хроническое системное воспаление. Представлено большое количество данных, характеризующих изменения отдельных параметров иммунной системы, метаболического статуса организма как при изолированных патологиях, так и при коморбидности ХОБЛ и МС. Ведется поиск статистически значимых ассоциаций патогенетических факторов с особенностями клинической картины синтропии, однако общая характеристика причинно-следственных связей, составляющих основу патогенеза коморбидности ХОБЛ и МС, в настоящее время отсутствует.

\section{ЗАКЛЮЧЕНИЕ}

При хорошо изученных аспектах возникновения и развития как ХОБЛ, так и МС, остается ряд вопросов, затрагивающих механизмы формирования коморбидной патологии. Например, являются ли изменения концентрации факторов воспаления вторичными по отношению к ХОБЛ или МС, либо они отражают прямую причину формирования одной из патологий в случае полипатии; какие факторы в большей степени вносят вклад в формирование системной воспалительной реакции и обусловливают особенности клинической картины коморбидности; какую роль играют нарушения метаболического статуса, характерные для MC, в механизмах иммунопатогенеза ХОБЛ, и др.

Необходимо дальнейшее изучение механизмов взаимоотягощающего влияния патогенетических факторов для формирования представлений о патогенетическом эндотипе синтропии ХОБЛ и МС. В прикладном аспекте эти знания могут стать основой для разработки способов персонализированной профилактики и патогенетической терапии сочетанной патологии, приводящей к формированию стойкого клинического эффекта в отношении как основного, так и сопутствующего заболевания.

\section{ДОПОЛНИТЕЛЬНАЯ ИНФОРМАЦИЯ}

Источники финансирования. Работа выполнена по инициативе авторов без привлечения финансирования.

Конфликт интересов. Авторы декларируют отсутствие явных и потенциальных конфликтов интересов, связанных с содержанием настоящей статьи.

Участие авторов. Воронкова О.В. - разработка концепции, составление плана рукописи, анализ публикаций, сбор и систематизация данных, касающихся этиологии и патогенеза ХОБЛ, метаболического синдрома и сочетанной патологии, написание основного текста статьи, формулировка выводов и заключения; Саприна Т.В. - анализ публикаций, систематизация данных, касающихся роли патогенетических факторов, ассоциированных с ожирением, в формировании коморбидной патологии, редактирование рукописи, внесение важных правок; Букреева Е.Б. - анализ публикаций, систематизация данных, касающихся спектра коморбидности ХОБЛ и клинико-патогенетических особенностей сочетанной патологии, редактирование рукописи, внесение важных правок; Зима А.П. - анализ публикаций, систематизация данных о роли факторов системного воспаления в патогенезе коморбидности ХОБЛ и метаболического синдрома, редактирование рукописи, внесение важных правок. Все авторы одобрили финальную версию статьи перед публикацией, выразили согласие нести ответственность за все аспекты работы, подразумевающую надлежащее изучение и решение вопросов, связанных с точностью или добросовестностью любой части работы.

\section{СПИСОК ЛИТЕРАТУРЫ | REFERENCES}

1. Ширинский В.С., Ширинский И.В. Коморбидные заболевания актуальная проблема клинической медицины // Сибирский медицинский журнал. - 2014. - Т. 29. - №1. - С. 7-12. [Shirinsky V.S., Shirinsky I.V. Comorbid diseases as an important problem of clinical medicine. The Siberian Journal of Clinical and Experimental Medicine. 2014;29(1):7-12. (In Russ.)]

2. Гудков Р.А., Коновалов О.Е. Коморбидность, мультиморбидность, полипатии - три взгляда на сочетанную патологию // Вестник
Российского университета дружбы народов. Серия: Медицина. 2015. — №1. - C.39-45. [Gudkov RA, Konovalov OE Komorbidnost', mul'timorbidnost', polipatii - tri vzgljada na sochetannuju patologiju. Vestnik Rossijskogo universiteta druzhby narodov. Serija: Medicina. 2015;(1):39-45. (In Russ.)]

3. Jiang S, Yang ZH, Chen YY, et al. MMP-9 genetic polymorphism may confer susceptibility to COPD. Genet Mol Res. 2016;15(2):1856-1883. doi: https://doi.org/10.4238/gmr.15026272 
4. Вютрих К.А., Куколь Л.В., Лазик В.В. Хроническая обструктивная болезнь легких и метаболический синдром: состояние проблемы (литературный обзор) // Вестник Санкт-Петербургского университета. Медицина. - 2017. — Т.12. - №1. - C.18-30. [Viutrikh KA, Kukol LV., LasikVV. Chronic obstructive pulmonary disease and the metabolic syndrome: The state of the problem (review). Vestnik of Saint Petersburg University. Medicine. 2017;12(1):18-30. doi: https://doi.org/10.21638/11701/spbu11.2017.102

5. Yuan C, Chang D, Lu G, Deng X. Genetic polymorphism and chronic obstructive pulmonary disease. Int J Chron Obstruct Pulmon Dis. 2017;12(1):1385-1393. doi: https://doi.org/10.2147/COPD.S134161

6. Li Y, Cho MH, Zhou X. What do polymorphisms tell us about the mechanisms of COPD? Clin Sci. 2017;131(24):2847-2863. doi: https://doi.org/10.1042/CS20160718

7. Negewo NA, Gibson PG, McDonald VM. COPD and its comorbidities: Impact, measurement and mechanisms. Respirology. 2015;20(8):1160-1171. doi: https://doi.org/10.1111/resp.12642

8. Chetty U, McLean G, Morrison D, Agur K, Guthrie B, Mercer SW. Chronic obstructive pulmonary disease and comorbidities: a large cross-sectional study in primary care. Br J Gen Pract. 2017;67(658):e321-e328. doi: https://doi.org/10.3399/bjgp17X690605

9. Barnes PJ. Senescence in COPD and Its Comorbidities. Annu Rev Physiol. 2017;79(1):517-539. doi: https://doi.org/10.1146/annurev-physiol-022516-034314

10. Global Strategy for Prevention, Diagnosis and Management of COPD, 2020 GOLD Report. Available at: https://goldcopd.org/gold-reports

11. Celli BR, Wedzicha JA. Update on Clinical Aspects of Chronic Obstructive Pulmonary Disease. Drazen JM, ed. N Engl J Med. 2019;381(13):1257-1266. doi: https://doi.org/10.1056/NEJMra1900500

12. Díez-Manglano J, Barquero-Romero J, Almagro P, et al. COPD patients with and without metabolic syndrome: clinical and functional differences. Drazen JM, ed. Intern Emerg Med. 2014;9(4):419-425. doi: https://doi.org/10.1007/s11739-013-0945-7

13. Cebron Lipovec N, Beijers RJHCG, van den Borst $B$, et al. The prevalence of metabolic syndrome in chronic obstructive pulmonary disease: a systematic review. COPD J Chronic Obstr Pulm Dis. 2016:13(3):399-406. doi: https://doi.org/10.3109/15412555.2016.1140732

14. James BD, Jones A V, Trethewey RE, Evans RA. Obesity and metabolic syndrome in COPD: Is exercise the answer? Chron Respir Dis. 2018;15(2):173-181. doi: https://doi.org/10.1177/1479972317736294

15. Piazzolla G, Castrovilli A, Liotino V, et al. Metabolic syndrome and Chronic Obstructive Pulmonary Disease (COPD): The interplay among smoking, insulin resistance and vitamin D. Loukides S, ed. PLoS One. 2017;12(10):e0186708. doi: https://doi.org/10.1371/journal.pone.0186708

16. Новиков Д.К., Смирнова О.В. Иммунологические фенотипы хронической обструктивной болезни легких: перспективы иммунокоррекции // Вестник Витебского государственного медицинского университета. — 2014. - Т.13. — №4. C.102-109. [Novikov DK, Smirnova OV. Immunologicheskie fenotipy hronicheskoj obstruktivnoj bolezni legkih: perspektivy immunokorrekcii. Vestnik Vitebskogo gosudarstvennogo medicinskogo universiteta. 2014;13(4):102-109. (In Russ.)]

17. Овчаренко С.И., Хроническая обструктивная болезнь легких: руководство для практикующих врачей / под ред. А. Г. Чучалина. -М.: ГЭОТАР-Медиа, 2016. - 192 с.

18. Barnes PJ. Cellular and molecular mechanisms of asthma and COPD. Clin Sci. 2017;131(13):1541-1558. doi: https://doi.org/10.1042/CS20160487

19. Stockley RA, Halpin DMG, Celli BR, Singh D. Chronic Obstructive Pulmonary Disease Biomarkers and Their Interpretation. Loukides S, ed. Am J Respir Crit Care Med. 2019;199(10):1195-1204. doi: https://doi.org/10.1164/rccm.201810-1860SO

20. Barnes PJ. Inflammatory mechanisms in patients with chronic obstructive pulmonary disease. J Allergy Clin Immunol. 2016;138(1):16-27. doi: https://doi.org/10.1016/j.jaci.2016.05.011

21. Wang $\mathrm{H}$, Ying $\mathrm{H}$, Wang $\mathrm{S}$, et al. Imbalance of peripheral blood Th17 and Treg responses in patients with chronic obstructive pulmonary disease. Clin Respir J. 2015;9(3):330-341. doi: https://doi.org/10.1111/crj.12147

22. Cosmi L, Liotta F, Annunziato F. Th17 regulating lower airway disease. Curr Opin Allergy Clin Immunol. 2016;16(1):1-6. doi: https://doi.org/10.1097/ACI.0000000000000227
23. Калинина Е.П., Виткина ТИ, Кнышова В В. и др. Клиникоиммунологическое сопоставление при Тh-зависимых механизмах иммунного ответа у больных хронической обструктивной болезнью легких // Медицинская иммунология. - 2018. T. 20. — №6. - C. 855-864. [Kalinina EP, Vitkina TI, Knyshova V V., et al. Clinical and immunological comparisons in Th-dependent immune response mechanisms among patients with chronic obstructive pulmonary disease. Medical Immunology (Russia). 2018;20(6):855-864 (In Russ.)] doi: https://doi.org/10.15789/1563-0625-2018-6-855-864

24. Смирнова О.В. Выявление аутоантител к эластину, коллагену І типа, коллагену IV типа при хронической обструктивной болезни легких и эмфиземе // Иммунопатология, аллергология, инфектология. — 2015. - №2. - C.84-93. [Smirnova OV. Vyjavlenie autoantitel k jelastinu, kollagenu I tipa, kollagenu IV tipa pri hronicheskoj obstruktivnoj bolezni legkih i jemfizeme. Immunopatologija, allergologija, infektologija. 2015;(2):84-93. (In Russ.)]

25. van der Weerd K, Dik WA, Schrijver B, et al. Morbidly Obese Human Subjects Have Increased Peripheral Blood CD4+ T Cells With Skewing Toward a Treg- and Th2-Dominated Phenotype. Diabetes. 2012:61(2):401-408. doi: https://doi.org/10.2337/db11-1065

26. Танченко О.А., Нарышкина С.В., Решетникова Л.К. Особенности иммунного статуса у больных с метаболическим синдромом // Дальневосточный медицинский журнал. — 2014. — №2. C. 20-23. [Tanchenko OA, Naryshkina SV, Reshetnikova LK. Osobennosti immunnogo statusa u bol'nyh s metabolicheskim sindromom. Dal'nevostochnyj medicinskij zhurnal. 2014;(2):20-23. (In Russ.)]

27. Shirakawa K, Yan X, Shinmura K, et al. Obesity accelerates $T$ cell senescence in murine visceral adipose tissue. J Clin Invest. 2016;126(12):4626-4639. doi: https://doi.org/10.1172/JCl88606

28. Agrawal M, Kern PA, Nikolajczyk BS.

The Immune System in Obesity: Developing Paradigms Amidst Inconvenient Truths. Curr Diab Rep. 2017;17(10):87. doi: https://doi.org/10.1007/s11892-017-0917-9

29. Endo Y, Yokote $K$, Nakayama T. The obesity-related pathology and Th17 cells. Cell Mol Life Sci. 2017;74(7):1231-1245. doi: https://doi.org/10.1007/s00018-016-2399-3

30. Недомолкина С.А., Золоедов В.И., Великая О.В. Цитокины у больных ХОБЛ в сочетании с сахарным диабетом 2 типа // Здоровье и образование в XXI веке. - 2018. - Т. 20. —№2. C. 75-78. [Nedomolkina SA, Zoloedov VI, Velikaya OV. Cytokines in patients with COPD combined with diabetes mellitus 2 type. J Sci Artic Heal Educ Millenn. 2018;20(2):75-78. (In Russ.)] doi: https://doi.org/10.26787/nydha-2226-7425-2018-20-2-75-78

31. Boriek AM, Lopez MA, Velasco C, et al. Obesity modulates diaphragm curvature in subjects with and without COPD. Am J Physiol Integr Comp Physiol. 2017;313(5):R620-R629. doi: https://doi.org/10.1152/ajpregu.00173.2017

32. Dixon $A E$, Peters U. The effect of obesity on lung function. Expert Rev Respir Med. 2018;12(9):755-767. doi: https://doi.org/10.1080/17476348.2018.1506331

33. Беспалова И.Д., Рязанцева Н.В., Калюжин В.В., и др. Системное воспаление в патогенезе метаболического синдрома и ассоциированных с ним заболеваний // Сибирский медицинский журнал (Иркутск). - 2013. - Т. 117. №2. - C. 5-9. [Bespalova ID, Rjazanceva NV, Kaljuzhin V., et al. Sistemnoe vospalenie $v$ patogeneze metabolicheskogo sindroma i associirovannyh s nim zabolevanij. Sibirskij medicinskij zhurnal (Irkutsk). 2013;117(2):5-9. (In Russ.)]

34. Крюков Н.Н., Гинзбург М.М., Киселева Е.В. Современный взгляд на роль асептического воспаления жировой ткани в генезе ожирения и метаболического синдрома // Артериальная гипертензия. - 2013. - T. 19. - №4. C. 305-310. [Kryukov NN, Ginzburg MM, Kiseleva EV. Up-todate view at the role of aseptic inflammation of adipose tissue in the genesis of obesity and metabolic syndrome. Arterialnaya Gipertenziya. 2013;19(4):305-10. In Russ.) doi: https://doi.org/10.18705/1607-419X-2013-19-4-

35. McCracken E, Monaghan M, Sreenivasan S. Pathophysiology of the metabolic syndrome. Clin Dermatol. 2018:36(1):14-20. doi: https://doi.org/10.1016/j.clindermatol.2017.09.004

36. Breyer M-K, Spruit MA, Hanson CK, et al. Prevalence of Metabolic Syndrome in COPD Patients and Its Consequences. Devaney J, ed. PLoS One. 2014;9(6):e98013. doi: https://doi.org/10.1371/journal.pone.0098013 
37. Baffi CW, Wood L, Winnica D, et al. Metabolic Syndrome and the Lung. Chest. 2016;149(6):1525-1534. doi: https://doi.org/10.1016/i.chest.2015.12.034

38. Coats V, Després J-P, Alméras N, et al. Ectopic adiposity and cardiometabolic health in COPD. Devaney J, ed. Int J Chron Obstruct Pulmon Dis. 2018;13(6):3331-3340. doi: https://doi.org/10.2147/COPD.S168963

39. Земсков А.М., Земсков В.М., Земскова В.А., и др. Метаболический иммунитет // Вестник Воронежского государственного университета. Серия: Химия. Биология. Фармация. - 2016. № 2. - C. 41-49. [Zemskov AM, Zemskov VM, Zemskova VA, et al. Metabolicheskij immunitet. Vestnik Voronežskogo gosudarstvennogo universiteta. Himiâ biologiâ. 2016;2:41-49. (In Russ.)]

40. Akpinar EE, Akpinar S, Ertek S, et al. Systemic inflammation and metabolic syndrome in stable COPD patients. Tuberk Toraks. 2012;60(3):230-237. doi: https://doi.org/10.5578/tt.4018

41. Naseem S, Baneen U. Systemic inflammation in patients of chronic obstructive pulmonary disease with metabolic syndrome. J Fam Med Prim Care. 2019;8(10):3393. doi: https://doi.org/10.4103/jfmpc.jfmpc_482_19

42. Овсянников Е.С., Авдеев С.Н., Будневский А.В. Системное воспаление у больных хронической обструктивной болезнью легких и ожирением // Терапевтический архив. - 2020. T. 92. - №3. - C. 13-18. [Ovsyannikov ES, Avdeev SN, Budnevsky AV. Systemic inflammation in patients with chronic obstructive pulmonary disease and obesity. Terapevticheskii arkhiv. 2020;92(3):13 18. (In Russ.) doi: https://doi.org/10.26442/00403660.2020.03.000265

43. Ступницкая А.Я. Оксидантно-антиоксидантный статус больных хронической обструктивной болезнью легких, сочетающейся с метаболическим синдромом // Современная медицина: актуальные вопросы. — 2013. — №23. - C.37-45. [Stupnickaja AJa. Oksidantno-antioksidantnyj status bol'nyh hronicheskoj obstruktivnoj bolezni legkih, sochetajushhejsja s metabolicheskim sindromom. Sovremennaja medicina: aktual'nye voprosy. 2013;(23):37-45. (In Russ.)]

44. Рязанов А.С., Киреев С.А., Еременко Н.Н. Влияние индекса массы тела на параметры спирографии у больных ХОБЛ в сочетании с метаболическим синдромом // Биомедицина. — 2010. — №4. C.119-121. [Rjazanov AS, Kireev SA, Eremenko NN. Vlijanie indeksa massy tela na parametry spirografii u bol'nyh HOBL v sochetanii s metabolicheskim sindromom. Biomedicina. 2010;(4):119-121. (In Russ.)]

45. Рязанов А.С., Киреев С.А., Еременко Н.Н. Особенности клинического течения ХОБЛ при метаболическом синдроме: роль системного воспаления // Ожирение и метаболизм. 2010. - T. 7. — №2. - C.49-51. [Ryazanov AS, Kireev SA,
Eremenko NN. Osobennosti klinicheskogo techeniya KhOBLpri metabolicheskom sindrome: rol' sistemnogovospaleniya. Obesity and metabolism. 2010;7(2):49-51. (In Russ.)] doi: https://doi.org/10.14341/2071-8713-5209

46. Рязанов А.С., Киреев С.А., Еременко Н.Н. Спирографические характеристики пациентов с ХОБЛ и метаболическим синдромом в зависимости от массы тела // Ожирение и метаболизм. - 2010. - T.7. — №3. - C. 28-30. [Ryazanov AS, Kireev SA, Eremenko NN. Spirograficheskie kharakteristiki patsientov s KhOBL i metabolicheskim sindromom v zavisimosti ot massy tela. Obesity and metabolism. 2010;7(3):28-30. doi: https://doi.org/10.14341/2071-8713-4980

47. Küpeli E, Ulubay G, Ulasli SS, et al. Metabolic Syndrome is associated with increased risk of acute exacerbation of COPD: a preliminary study. Endocrine. 2010;38(1):76-82 doi: https://doi.org/10.1007/s12020-010-9351-3

48. Филатова Ю.И., Перфильева М.В., Чернов А.В. Особенности клиники и терапии хронической обструктивной болезни легких на фоне метаболического синдрома // Молодой ученый. 2014. — №7. - C.220-222. [Filatova Jul, Perfil'eva MV, Chernov AV. Osobennosti kliniki i terapii hronicheskoj obstruktivnoj bolezni legkih na fone metabolicheskogo sindroma. Molodoj uchenyj. 2014;(7):220-222. (In Russ.)]

49. Кожевникова С.А., Будневский А.В., Овсянников Е.С., Белов В.Н. Особенности клинического течения и качества жизни пациентов с хронической обструктивной болезнью легких на фоне метаболического синдрома // Медицинский вестник Северного Кавказа. - 2017. - T. 12. - №1. - C.20-23. [Kozhevnikova S, Budnevskiy A, Ovsyannikov E, Belov V. Particularity of the clinical course and quality of life of patients with chronic obstructive pulmonary disease on the background of the metabolic syndrome. Medical news of the North Caucasus. 2017;12(1):76-82. doi: https://doi.org/10.14300/mnnc.2017.12006

50. Choi HS, Rhee CK, Park YB, et al. Metabolic Syndrome in Early Chronic Obstructive Pulmonary Disease: Gender Differences and Impact on Exacerbation and Medical Costs. Int J Chron Obstruct Pulmon Dis. 2019;14(1):2873-2883. doi: https://doi.org/10.2147/COPD.S228497

51. Будневский А.В., Овсянников Е.С., Мальцева Ю.С., и др. Особенности течения хронической обструктивной болезни легких на фоне метаболического синдрома // Наука молодых (Eruditio Juvenium). - 2020. - T. 8. — №2. — C. 164-171. [Budnevsky AV, Ovsyannikov ES, Maltseva YN, et al. Peculiarities of course of chronic obstructive pulmonary disease with underlying metabolic syndrome. Nauka molodyh. 2020;8(2):164-171. doi: https://doi.org/10.23888/HMJ202082164-171

\section{ИНФОРМАЦИЯ ОБ АВТОРАХ [AUTHORS INFO]:}

*Воронкова Ольга Владимировна, д.м.н. [Olga V. Voronkova, MD, PhD]; адрес: Россия, 634050, Томск, Московский тракт, д. 2, строение 16 [address: 2/16 Moskovskij trakt street, 634050 Tomsk, Russia]; ORCID: https://orcid.org/0000-0001-9478-3429; eLibrary SPIN: 8005-8110; e-mail: voronkova-ov@yandex.ru

Саприна Татьяна Владимировна, д.м.н. [Tatyana V. Saprina, MD, PhD]; ORCID: https://orcid.org/0000-0001-9011-8720; eLibrary SPIN: 2841-2371; e-mail: tanja.v.saprina@mail.ru

Букреева Екатерина Борисовна, д.м.Н., профессор [Ekaterina B. Bukreeva, MD, PhD, Professor]; ORCID: https://orcid.org/0000-0002-7699-5492; eLibrary SPIN: 6553-9690; e-mail: kbukreeva@mail.ru

Зима Анастасия Павловна, д.М.н. [Anastasia P. Zima, MD, PhD]; ORCID: https://orcid.org/0000-0002-9034-7264; eLibrary SPIN: 5710-4547; e-mail: zima2302@gmail.com

*Автор, ответственный за переписку / Corresponding author.

\section{ЦИТИРОВАТЬ:}

Воронкова О.В., Саприна Т.В., Букреева Е.Б., Зима А.П. Этиопатогенетические параллели и нерешенные вопросы патогенеза коморбидности хронической обструктивной болезни легких и метаболического синдрома (обзор литературы) // Ожирение и метаболизм. - 2020. - Т. 17.— №3. - C. 292-298. doi: https://doi.org/10.14341/omet12378

\section{TO CITE THIS ARTICLE:}

Voronkova OV, Saprina TV, Bukreeva EB, Zima AP. Etiopathogenetic parallels and unresolved issues of pathogenesis of comorbidity COPD and metabolic syndrome (review). Obesity and metabolism. 2020;17(3):292-298. doi: https://doi.org/10.14341/omet12378 